\title{
Empirical Research on the Influences of Different Layout Designs of HR Management on the Motivation of Employees Based on Fuzzy Comprehensive Evaluation
}

\author{
Jing Sun \\ Business School, Jiujiang University, Jiujiang, China \\ jings_un@yeah.net
}

\begin{abstract}
Keywords:layout design; fuzzy comprehensive evaluation; production distribution; judgment matrix; membership degree
\end{abstract}

\begin{abstract}
With the high speed development of modern equipments of today, optimizing organization layout structure can improves the efficiency of organizational agility and vitality and adapts to the change of market environment rapidly. The staff's working motivation has important influence on the process from development of machinery and equipment to the operation of the equipment. The current production distribution is designed by engineers and managers from the angle of production technology. Although the design pays attention to the production activities of technical and continuity it often ignores the employee's own production motivation and enthusiasm. This paper mainly focuses on four different layout employee motivation and production efficiency. The valuable data can be calculated through analyze the different layouts of employee motivation by fuzzy comprehensive evaluation method which can design the layout form reasonable, stimulate work motivation of staff and realize lean production.
\end{abstract}

\section{Introduction}

Working environment has a great influence on the mood, moral, behavior and thinking of employees. At present, with the reform in the political, economic, cultural and many other fields, more and more enterprises applicate scientific management methods and modern technology in the design the enterprise production layout and provide a good working environment to staff. Comfortable working environment and positive work motivation are helpfull for the creative production and efficiency of work. In addition, the environment will also increase the staff's sense of responsibility and teamwork spirit[1]. When a person is in good physical and mental state, his spirit of the work will concentrate on work more. In the production organization, this kind of environment come from reasonable assembly line layout design. It can raise the enthusiasm of the employees, increase the synergistic effect between them and improve the production efficiency.

In the process of enterprise human resources management, people put forward higher requirements to the visual representation of the performance results. Managements can evaluate enterprise's efficiency and management effect according to the data which can measured and accurate of working efficiency effect and can improve the scientificalness and rationality of decisionmaking more through the evaluation of quantitative results and effect completion .The influence of staff's work motivation on machinery and equipment efficiency is strong. The researchers try to study the advantages and disadvantages of the different layout designs and put forward an effective and feasible solution to maximise the guide and inspire the motivation of employees. A good example is the honeycomb layout which is not only conform to the product layout of mass production but also is agile and diverse.

This paper analyzes different layout designs of employee motivation through the fuzzy comprehensive evaluation method and obtains the results and put forward the effect of different layout designs on employee motivation through the data. It provides the theory reference and data basis for enterprise layout design, and promotes the change of employees from staff recruitment and organization work, job promotion, training, salary and welfare and performance of information management. 


\section{Theoretical basis}

A. The feasibility analysis of layout design

Layout design in the enterprise unit production activity is defined as design about devices, machinery, equipments and personnel factors and so on in order to accomplish organizational goals . In the production process of raw materials, information and material, flow is an important factor of the layout design. Machinery and equipment specified tiny change will have great influence on production cost and efficiency.

There are four main categories of machinery industry layout: permanent position layout, process layout, product distribution, honeycomb layout.

1) permanent position layout

In this kind of layout mode, finally product must be complete in the specified location due to large-scale,heavy weight, fragile quality of material and other reasons.So, machinery, tools and workers act around even in a relatively fixed position[2]. This means that this kind of layout is the layout which production activities are producted around, unlike other layout which material flowed between the mechanical workshops.

For example, the position is relatively fixed in the process of shipbuilding, because the product is overweight, too heavy , inconvenience.

The main problem of this layout is the space will be assigned to different contractor .So the conflicts should be avoid in product process and the spatial position of each contractor must be clear and definite .

2) process layout

In this layout, the mechanical and products are located in a certain range, related activities are completed in a specific way because of the diversity of production and service. For instance, in a factory, the welding workshop, stamping workshop, chop shop needs to ensure in a certain distance according to the special process.

3) product distribution

In this layout, the production activities are completed in accordance with the order of production. Each site plans production activities detailed and transfers to the next site. This kind of production distribution also called assembling line. The biggest characteristic of this layout is large-scale and diversity[3].Some products can be assembled in the same time in and the same production line.

The characteristics of the product layout design is as follows:This layout usually needs professional machinery and professional equipment.So, this kind of layout needs large investment. Other characteristic of this layout is that production activities is divided into many independent relatively simple activity. The production activities are repeated, monotonous. In this layout ,activities of employees are simple and repeated and skilled staff are not needed.

4) honeycomb layout

This layout is combination of the product and process which has the advantage of both process layout and product layout. This kind of layout has both the flexibility of process layout production also has the scale of product layout. . This layout could form a relatively independent small production workshop according to the production and process of similarity.

$B$. The relationship between layout design and employee motivation

Elton Mayo puts forward the concept of staff motivation in the study. Since then, Maslow, Herzberg, Brent Chad researchs the staff motivation and incentive theory. In this paper, we reference the simple motivation concept.

Motivation is a people want to do something and psychological thinking way and is also a mind of making some decisions at the same time[4]. The personal motivation theory is divided into two categories: consciousness hypothesis motivation is produced according to the personal needs which is unconscious such as maslow's hierarchy of needs, McGregor X, Y theory, Herzberg's double factors theory and so on .The other is assumption motivation which is based on the foreseeable goals such as the equity theory of Adams and expectations theory of Epharum.

This paper analyzes the influence of different layout design on staff motivation according to experts proposed motivation indicators which include incentive motivation, plan motivation, coordination motivation ,implement motivation, leadership motivation and communication motivation. Incentive motivation is to make staff psychological satisfaction by getting material, realize the improvement and development of motivation[5]. In the short term plan motivation is seeking self-fulfillment planning motivation. Coordinate motivation refers to the adaptability in the different environment. Leadership motivation refers to promotion motivation. Communication motivation comes from team incentive theory which suggest that good communication between the 
staff is helpfull to the building of a good working environment.

According to the theory of motivation, it has a great influence on person's mood, ethics, behavior and thinking . Comfortable working environment and positive work motivation is not only helpful to the generation of new idea and the improvement of work efficiency but also improve the staff's sense of responsibility and teamwork spirit. When a person is in good physical and mental state, his spirit of the work will be more focused than usual[6]. In the production organization, this kind of environment come from reasonable assembly line layout design. It can raise the enthusiasm of the employees, increase the synergistic effect between them and improve the production efficiency.

\section{The construction of fuzzy comprehensive evaluation model}

The operation steps of fuzzy comprehensive evaluation model are as follows[7-9]:

The first step, determine the fuzzy evaluation set $\mathrm{U}=\left\{u_{1}, u_{2}, \ldots, u_{n}\right\}$ according to the target;

The second step, determine evaluation factors $\mathrm{V}=\left\{v_{1}, v_{2}, \ldots, v_{m}\right\}$;

The third step, describe membership of fuzzy evaluation set $u_{1}, u_{2}, \ldots, u_{n}$ in $\mathrm{U}$ use evaluation factors $v_{1}, v_{2}, \ldots, v_{m}$ in $\mathrm{V}$, Membership can get through the group's score.So,it can get the fuzzy factors evaluation matrix[10]:

$$
R_{i j}(i=1,2 \ldots n, j=1,2 \ldots, m)
$$

The fourth step, analyze evaluation and score of group through the investigation and obtain the comparative judgment matrix; then, normalized the comparative judgment matrix ; the result is[11]:

$$
X_{i j}=\left(\frac{a_{i j}}{\sum_{i=1}^{n} a_{i j}}\right)
$$

The fifth step, obtain

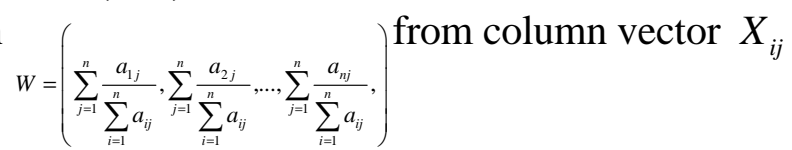

The sixth step, normalized $W$ and abtain ordering vector $W=\left(w_{1}, w_{2}, . ., w_{n}\right)^{T}$

The seventh step, obtain the $\max (B)$ by fuzzy transformation $B=W \times R$. According to the results will be calculated according to the principle of maximum membership degree .

\section{The empirical analysis of HR management factor model}

First, establish an expert evaluation set $\mathrm{U}$, The first layer index set is $\mathrm{P}\{$ honeycomb layout design, the product layout design, process layout design, fixed position layout design $\}$, The second layer index set is \{ Incentive motivation, plan motivation, coordination motivation ,implementation motivation , leadership motivation and communication motivation $\}$, which is shown in Figure 1.

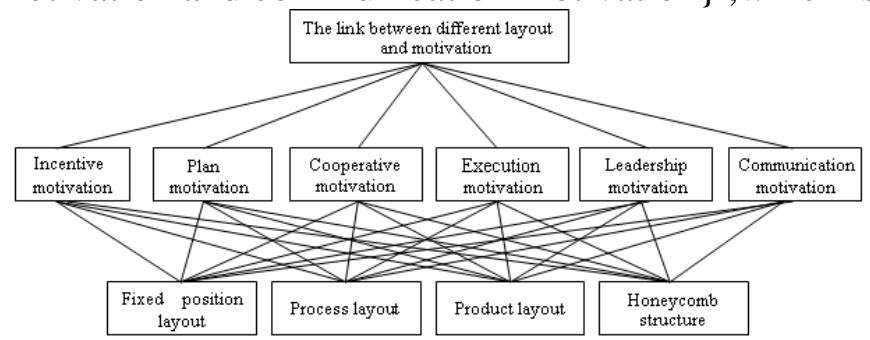

Figure 1. Layout design and hierarchical structure graph of employee motivation

Then, the definition of the evaluation set is $V=\{$ best, good, pass, fail $\}$. The weight $W 1$ of the first layer can be calculated through the matrix . The value rules of comparative judgment matrix $x_{i j}$ can be seen in Table 1 . 
TABLE I. THE VALUE RULE OF ELEMENT $\boldsymbol{X}_{i j}$

\begin{tabular}{|l|l|l|}
\hline \multicolumn{1}{|c|}{ element } & \multicolumn{1}{|c|}{ scaling } & \multicolumn{1}{c|}{ rules } \\
\hline \multirow{4}{*}{$X_{i j}$} & 1 & I and $\mathrm{j}$ are equally important \\
\cline { 2 - 3 } & 3 & i is slightly more important than $\mathrm{j}$ \\
\cline { 2 - 3 } & 5 & i is more important than $\mathrm{j}$ obvious \\
\cline { 2 - 3 } & 7 & i is very important than $\mathrm{j}$ \\
\cline { 2 - 3 } & 9 & i is important than $\mathrm{j}$ extremely \\
\hline
\end{tabular}

Table 2 and table 3 can calculate the quantitative unqualitative results through the questionnaire and the way of expert interview .

In order to get accurate quantification of human resource management in different layout, it need to determine the first layer index set which includes honeycomb layout design $u_{1}$, product layout design $u_{2}$ process layout design $u_{3}$ and fixed layout design $u_{4}$. Table 2 shows the scores of experts of first layer index.

TABLE II. THE SCORE OF FIRST SET INDICATORS

\begin{tabular}{|c|c|c|c|}
\hline $\begin{array}{c}u_{1} \text { honeycomb } \\
\text { layout } \\
\text { design }\end{array}$ & $\begin{array}{c}u_{2} \text { Product } \\
\text { layout } \\
\text { design } \\
\end{array}$ & $\begin{array}{c}u_{3} \text { Process } \\
\text { layout } \\
\text { design } \\
\end{array}$ & $\begin{array}{l}u_{4} \text { fixed } \\
\text { layout } \\
\text { design }\end{array}$ \\
\hline 1 & 0.2 & 3 & 0.13 \\
\hline 5 & 1 & 0.33 & 5 \\
\hline 0.33 & 3 & 1 & 0.18 \\
\hline 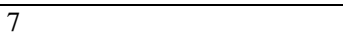 & 0.2 & 6 & 1 \\
\hline
\end{tabular}

Comparative judgment matrix $\mathrm{X}$ and The first layer index weight ${ }^{W_{1}}$ can be calculated from Table 2:

$$
X=\left[\begin{array}{cccc}
1 & 0.2 & 3 & 0.13 \\
5 & 1 & 0.33 & 5 \\
0.33 & 3 & 1 & 0.18 \\
7 & 0.2 & 6 & 1
\end{array}\right]
$$

the sum is the following[12]:

$$
X_{i j}=\left[\begin{array}{llll}
0.057 & 0.026 & 0.276 & 0.011 \\
0.284 & 0.130 & 0.028 & 0.285 \\
0.017 & 0.390 & 0.092 & 0.013 \\
0.400 & 0.026 & 0.553 & 0.075
\end{array}\right]=\left[\begin{array}{l}
1.448 \\
1.130 \\
1.152 \\
1.105
\end{array}\right]
$$

and the weight $W_{1}=\left[\begin{array}{l}0.23 \\ 0.15 \\ 0.18 \\ 0.17\end{array}\right]$ can be calculated by normalized $\mathrm{X}_{\mathrm{ij}}$.

$$
W_{1}=\left[\begin{array}{l}
0.23 \\
0.15 \\
0.18 \\
0.17
\end{array}\right] \text { can be calculated by normalized } \mathrm{X}_{\mathrm{ij}} \text {. }
$$

In order to get accurate quantification of human resource management in different layout, it need to determine the second layer index set which includes excited motivation, plan motivation, coordination motivation, implementation motivation, leadership motivation and communication motivation. Table 3 shows the scores of experts of second layer index.

So,

$$
R_{1}=\left[\begin{array}{l}
0.7 \\
0.4 \\
0.3
\end{array}\right] \quad R_{2}=\left[\begin{array}{l}
0.6 \\
0.2 \\
0.2
\end{array}\right] \quad R_{3}=\left[\begin{array}{l}
0.8 \\
0.4
\end{array}\right] \quad R_{4}=\left[\begin{array}{l}
0.7 \\
0.6 \\
0.8
\end{array}\right] \quad R_{5}=\left[\begin{array}{l}
0.4 \\
0.6 \\
0.7
\end{array}\right] R_{5}=\left[\begin{array}{l}
0.6 \\
0.3 \\
0.5
\end{array}\right]
$$

The weights of second layer are $W_{21}, W_{22}, W_{23}, W_{24}, W_{25}, W_{26}$. The second index level comprehensive evaluation matrix $B_{1}=W_{21} \times R_{1}=\left[\begin{array}{lll}0.49 & 0.36 & 0.15\end{array}\right]$ can be calculated using the equation $B=W \times R$.

$$
\begin{gathered}
B_{2}=W_{22} \times R_{2}=\left[\begin{array}{ccc}
0.32 & 0.42 & 0.26
\end{array}\right] B_{3}=W_{23} \times R_{3}=\left[\begin{array}{ccc}
0.46 & 0.14 & 0.22
\end{array}\right] B_{4}=W_{24} \times R_{4}=\left[\begin{array}{lll}
0.67 & 0.26 & 0.07
\end{array}\right] \\
B_{5}=W_{25} \times R_{5}=\left[\begin{array}{ll}
0.59 & 0.41
\end{array}\right] \\
B_{6}=W_{26} \times R_{6}=\left[\begin{array}{lll}
0.48 & 0.25 & 0.27
\end{array}\right]
\end{gathered}
$$

B can calculated according to the equation $B=\left(B_{1} B_{2} B_{3} B_{4} B_{5} B_{6}\right)^{T}$.

So, The total evaluation of first layer is as follows[13]. 


$$
\begin{aligned}
P & =W_{1}^{T} \times B=\left(\begin{array}{llll}
0.23 & 0.15 & 0.18 & 0.17
\end{array}\right) \times\left[\begin{array}{cccc}
0.49 & 0.36 & 0.15 & 0 \\
0.32 & 0.42 & 0.26 & 0 \\
0.64 & 0.14 & 0.22 & 0 \\
0.67 & 0.26 & 0.07 & 0 \\
0.59 & 0.41 & 0 & 0 \\
0.48 & 0.25 & 0.27 & 0
\end{array}\right]
\end{aligned}
$$

According to the membership degree, it is known that the honeycomb layout design is the best. When ${ }^{u_{1}}$ regarded as the perfect membership, the result is 0.531 . When ${ }^{u_{1}}$ regarded as the good me membership, the result is 0.308 . When ${ }^{u_{1}}$ regarded as the pass membership, the result is0.159. When $u_{1}$ regarded as the fail membership, the result is 0 . This layout design is the best to plan the level of staff mind which can stimulate the staff's working enthusiasm maximum.

TABLE III. THE SCORE AND INDEX WEIGHT OF SECOND SET INDICATORS(FULL MARKS: 10)

\begin{tabular}{|c|l|l|l|l|l|l|}
\hline Index & $\begin{array}{c}\text { Excited } \\
\text { motivation }\end{array}$ & $\begin{array}{c}\text { Plan } \\
\text { motivation }\end{array}$ & $\begin{array}{c}\text { Coordination } \\
\text { motivation }\end{array}$ & $\begin{array}{c}\text { implementation } \\
\text { motivation }\end{array}$ & $\begin{array}{c}\text { Leadership } \\
\text { motivation }\end{array}$ & $\begin{array}{c}\text { Communication } \\
\text { motivation }\end{array}$ \\
\hline Score(Full marks: 10) & 6.2 & 7.8 & 8.0 & 8.8 & 7.6 & 8.2 \\
\hline best & 0.7 & 0.6 & 0.8 & 0.7 & 0.4 & 0.6 \\
\hline good & 0.4 & 0.2 & 0.4 & 0.6 & 0.6 & 0.3 \\
\hline pass & 0.3 & 0.2 & 0 & 0.8 & 0.7 & 0.5 \\
\hline fail & 0 & 0 & 0 & 0 & 0 & 0 \\
\hline
\end{tabular}

\section{Conclusion}

The outstanding characteristic of modern human resources management is personalized, It pays attention to the differences of individual person, determines and guides the development of different directions, and unifies person individual work motivation and long-term interests of enterprise. The analysis of different layout employee motivation not only can reinforce enterprise talent team but also play an important role to the ascension of the decision-making talents and the development of planning. This paper studies the different layout designs of employee motivation through the fuzzy comprehensive evaluation method, solves the big subjective optional problem of evaluation process. It can point out that the accurate quantitative data for analysis evaluation. Through the analysis of the data ,we can see that the effect of honeycomb layout design on staff motivation is most obvious. Honeycomb layout design management can inspire staff enthusiasm well in the enterprise which can improve enterprise efficiency in long terms.

\section{References}

[1] Bilian Yao,Zhongbin Li.Summarization of $\mathrm{HR}$ in quantitative method.Value engineering, 2009(02):12-13

[2] Xisong Liu,Dejiang Zhang. Application of Fuzzy mathematics in the human resources performance evaluation . Business research, 2008(05):13-15

[3] Zhongbao Pan,Mingxia Wei. The fuzzy comprehensive evaluation research of Human resources management performance.Journal of Jinan University,2010(9):45-50.

[4] Qichang Hu. The fuzzy evaluation of management information system.Scientific management ,2011(06):15-17.

[5] Liya Gu. The comprehensive evaluation method of human resources performance based on the fuzzy strategy . China science and technology information,2009(16):17-21

[6] Feifei Li,Meicui Wang. The application of fuzzy mathematics in performance evaluation. Contemporary economic, 2007(16):19-20

[7] Weihua Chen,Xiaoyan Liang. The application of fuzzy comprehensive evaluation in Personnel assessment .Value engineering, 2011(10):21-25.

[8] Wenyi Luo.Chengzhong Luo. The comprehensive decision model of interval number.System engineering theory and practice ,2011(10):12-17 
[9] Linyi Tang.The analysis model and meaning of Human resource performance assessment . Strategy and management,2009(10):21-22

[10] Weiliang Luo.The human resources allocation of personal-post dynamic matching model..Introduction and consulting,2010(05):12-13

[11] Bonian Li. The fuzzy mathematics and its application .Hefei university press,2009(02):3-8

[12] Peizhuang Wang. Fuzzy set theory and its application.Shanghai science and technology publishing house ,2008(01):21-22

[13] YueZhang. The fuzzy mathematics and its application. Coal industry press ,2011(02):21-23 